\title{
Niños y adolescentes frente a las nuevas tecnologías: Acceso y uso de las tecnologías educativas en las escuelas peruanas ${ }^{1}$
}

Children, teens and the new technologies: ICT' access and use in Peruvian schools

\author{
Patricia Ames \\ Instituto de Estudios Peruanos - Pontificia Universidad Católica del Perú \\ pames@iep.org.pe,pames@pucp.pe
}

Recibido: 1-8-2014

Aprobado: 14-9-2014

1 Este artículo se basa en un estudio más amplio titulado «Acceso, uso, apropiación y sostenibilidad de tecnologías educativas en I.E. del nivel primaria y secundaria: las perspectivas de los estudiantes», que fue financiado por el Ministerio de Educación del Perú mediante adjudicación directa selectiva No. 0046-2013-ED/UE 026. Los puntos de vista expresados en este artículo son, sin embargo, responsabilidad exclusiva de la autora y no representan necesariamente la posición del Ministerio de Educación. 


\title{
Resumen
}

La intensa distribución de tecnologías educativas que ha tenido lugar en las escuelas peruanas en la última década, sumada a una mayor disponibilidad de los mismos en el mercado (gracias al abaratamiento de costos y las facilidades para adquirirlos), parece estar cambiando aceleradamente el panorama tecnológico en las escuelas peruanas. Este artículo se pregunta por la forma en que esta masiva presencia de las TIC se traduce en el espacio escolar y cuáles son las perspectivas de los y las estudiantes de escuelas públicas sobre ellas. Ello parte de un estudio reciente en tres regiones del Perú, en seis localidades distintas de áreas urbanas y rurales, realizado tanto en primaria como en secundaria. Se exploran principalmente el acceso y las percepciones de los y las estudiantes de escuelas públicas sobre las tecnologías educativas, así como el uso que le dan a las mismas dentro y fuera de la escuela. La perspectiva de otros actores educativos -como docentes y directivos- son asimismo consideradas para comprender y poner en contexto las experiencias estudiantiles. El estudio revela la precariedad en el acceso que los estudiantes tienen a las tecnologías a pesar de su presencia en las escuelas y el uso todavía limitado que tienen estas tecnologías en los procesos de aprendizaje de los estudiantes tanto dentro como fuera de la escuela.

Palabras clave: niños, adolescentes, Tecnologías de Información y Comunicación (TIC), tecnologías educativas, Perú

\begin{abstract}
The intense distribution of educational technologies in Peruvian schools in the last decade along with a greater availability of ICT in the market (thanks to its affordability and greater presence) seems to be changing the technological landscape in Peruvian schools. This paper deals with the question of how this massive presence of ICT is appropriated in the school scenario and what are the students' perspectives on this. It departs form a recent study in three Peruvian regions, in six different communities, both rural and urban, and carried out in primary and secondary schools. It explores mainly students' access to ICT and how they use ICT inside and outside schools. Other actors' (such as teachers and principals) perspectives are also considered to understand and place into context the students' experiences. The study reveals the precariousness in students' access to educational technologies, despite their very presence in schools. It also shows the limited use of ICT in students' learning processes inside and outside schools.

Keywords: children, teens, Information and Comunication Technologies (ICT), educational technologies, Peru
\end{abstract}




\section{Niños y adolescentes frente a las nuevas tecnologías: Acceso y uso de las tecnologías educativas en las escuelas peruanas}

\section{Introducción}

Desde hace casi tres décadas, en el Perú, se han desarrollado diversos programas para integrar las Tecnologías de Información y Comunicación (TIC) al proceso educativo. En los últimos años, sin embargo, la inversión en TIC ha sido considerable, principalmente a través del programa «Una Laptop por Niño $»^{2}$, mediante el cual se han distribuido un total de 797.352 laptops a nivel nacional en el período 2008-2011, y 83.971 kits de robótica (Ministerio de Educación 2014). La intensa distribución de equipos TIC en la última década, sumada a una mayor disponibilidad de los mismos en el mercado (gracias al abaratamiento de costos y las facilidades para adquirirlos), parece estar cambiando aceleradamente el panorama tecnológico en las escuelas peruanas: de acuerdo con la Encuesta Nacional a Instituciones Educativas -Enedu 2011-, el $83,4 \%$ del total de escuelas primarias tenía computadoras. Si bien esta cifra aumentaba en las escuelas urbanas $(89,1 \%)$, no era nada despreciable en las escuelas rurales $(81,5 \%)$.

Este artículo se pregunta por la forma en que esta masiva presencia de las TIC se traduce en el espacio escolar y cuáles son las perspectivas de los y las estudiantes de escuelas públicas sobre ellas, pues resulta imprescindible conocer las formas de uso y apropiación de TIC por parte de niños y adolescentes para mejor aprovechar sus potencialidades para la enseñanza y el aprendizaje. Ello es aún más urgente si se toma en cuenta que son justamente los niños y jóvenes los que tienen un acercamiento mayor y más temprano a las TIC. Las perspectivas de otros actores educativos, como docentes y directivos, son asimismo valiosas para comprender y poner en contexto las experiencias estudiantiles. Debido a que el estudio se encuentra todavía en curso, este artículo aborda solo parte de la información recolectada ${ }^{3}$.

\section{Aproximación conceptual}

Las TIC aplicadas a la educación han generado un gran optimismo en la mayor parte de actores involucrados: los Estados y gobiernos; los empresarios y promotores de TIC; las familias, los propios niños y jóvenes, y los maestros. Estos

2 De acuerdo con la Digete (Ministerio de Educación), la inversión para el período 2008-2012 ha sido de S/. 303.850.112.

3 El estudio en el que se basa este artículo, titulado «Acceso, uso, apropiación y sostenibilidad de tecnologías educativas en I.E. del nivel primaria y secundaria: las perspectivas de los estudiantes», se realiza entre noviembre 2013 y setiembre 2014. 
últimos han mostrado posiciones ambivalentes, sobre todo, ante el temor de ver cuestionado su papel de trasmisor de conocimientos en un ámbito en el cual sus alumnos demuestran un mayor dominio (Trinidad y Rodríguez, 2012; Trinidad, 2005).

Sin embargo, no han sido pocas las críticas y evidencias contrarias a las visiones excesivamente optimistas. Como señala Ferres (2000), a pesar de su potencial, la escuela incorpora muchas veces las TIC de manera superficial, como una continuidad de las tecnologías tradicionales, que se usa como un simple soporte de la cultura verbal tradicional. Esto dialoga con lo que diversos estudios en nuestro medio (Villanueva y Olivera, 2012; Gutierrez, 2009; Laura, 2008; Trinidad, 2005) encuentran al investigar el uso pedagógico de las TIC por parte de los docentes: un conjunto de barreras y limitantes para su aprovechamiento. Ello va desde la inadecuada formación y capacitación de los docentes a cargo, hasta los sistemas de aprovisionamiento y mantenimiento de los equipos. De modo más general, el balance de Balarin (2013, p. 16) sobre las políticas educativas referidas a las TIC desde los años 1990 resalta la falta de claridad en los objetivos educativos de estas políticas. Asimismo, la autora identifica una inadecuada planificación, evaluación e implementación de los programas que las gestionan. Otros estudios preocupados por los bajos logros de aprendizaje que caracterizan a las escuelas públicas han buscado evidencias del impacto de la introducción de las TIC en dichos logros; sin embargo, no han encontrado un cambio en esa dirección (Santiago et ál., 2010; Cristia et ál., 2012).

No cabe duda de que las TIC en sus diversas modalidades tienen mucho que ofrecer para renovar y mejorar el aprendizaje y la enseñanza tradicional (Gee, 2004). A ello se debe sumar que los niños y jóvenes de hoy entran en contacto con ellas en la vida cotidiana y lo harán en el futuro en la vida laboral, de modo que se vuelve una necesidad ineludible el desarrollar un mejor conocimiento y dominio de las mismas. No obstante, atribuirles un poder de transformación en sí mismas puede oscurecer el hecho de que, por más novedosas y potentes que sean las tecnologías, estas son incorporadas en contextos sociales particulares por actores sociales específicos.

Al respecto, Kraemer, Dedrick y Sharma (2009), en su análisis de la propuesta de OLPC, reconocen que el uso de las TIC no puede aislarse del ambiente sociocultural. Más aun, nos recuerda que las TIC no son innovaciones discretas, sino sistémicas; y que su valor depende en gran medida de un ecosistema mas amplio que incluye el hardware, la infraestructura de conexión, las periferias, las aplicaciones, y servicios varios, desde la instalación, el mantenimiento y apoyo técnico hasta la capacitación, así como la creación de programas (software) y contenidos digitales. Del mismo modo Warschauer y Ames (2010), también para el caso de OLPC, enfatizan la importancia del contexto en el cual se insertan las TIC y las características tanto de estas como de los usuarios de las mismas y sus necesidades. Ello permite entender resultados muy diversos y contrarios al optimismo que mencionábamos al inicio. 
En ese sentido, y como se ha señalado respecto a viejas tecnologías (i.e. la escritura), para el caso de las nuevas, la pregunta no debería ser qué hace la tecnología con la gente, sino qué hace la gente con la tecnología (Street, 2000). Desde esta postura, resaltan los paralelismos entre literacidad y TIC. Este tema empieza a debatirse fructíferamente en este campo -como lo muestran Waeschauer y Toma (en este volumen)-, en el que nos interesa indagar qué está pasando actualmente en las escuelas y cuáles son las perspectivas de los niños y adolescentes frente a la mayor presencia de TIC en ellas.

Para ello, partimos de considerar que las TIC, de manera equivalente a la escritura (como tecnología de la palabra), no son únicamente un conocimiento técnico, una habilidad discreta, que produce cambios en las personas independientemente del contexto. Por el contrario, las TIC son una práctica social; es decir, están inmersas dentro de contextos sociales. Por ello, involucran comportamientos, valores y significados asociados a ellas, y están inscritas en las relaciones de poder y desigualdad que atraviesan la sociedad. Esta conceptualización, que proviene del campo de los Nuevos Estudios de Literacidad (Street 1993, 1995; Barton y Hamilton, 1998), evita caer en un optimismo excesivo que a veces ha llevado a considerar las TIC como la panacea para los males del sistema educativo (Trinidad, 2005; Balarin, 2013), sin irnos al extremo de un pesimismo que no les reconoce mayor mérito en el espacio educativo. Por el contrario, al observar los usos de los actores sociales concretos y los significados de las TIC en sus vidas, es posible identificar tanto los cambios positivos que se producen en el espacio social y educativo como las barreras que obstaculizarian dichos cambios y que son, entonces, posibles resolver. En términos prácticos, decidimos acercarnos al uso de las TIC en el espacio educativo no enfocado en un programa específico, sino abarcando la diversidad de recursos disponibles en cada escuela, y producto de diversos programas a lo largo de los últimos años, que es necesario presentar muy brevemente.

El programa más reciente (2007-2012) de introducción de TIC en el espacio escolar peruano es «Una Laptop por Niño» (conocido en la literatura como OLPC por sus siglas en inglés). Este programa distribuyó computadoras portátiles XO según dos modalidades: en un primer momento (2008-2010), se distribuyeron según el modelo 1 a 1 . Es decir, cada alumno de la escuela que recibía una laptop XO en propiedad podía llevarla a su casa y a la escuela, pero debía retornarla al finalizar el año escolar. Esta era una característica crucial del modelo OLPC, que proponía la indagación y uso libre por parte del estudiante, basado en una pedagogía construccionista. Esta ha sido la modalidad más publicitada. Posteriormente, en el año 2010, y debido a la falta de recursos, se cambia de modalidad para entregar un paquete de XO por escuela, ya no por niño. Ello pasa a ser denominado Centro de Recursos Tecnológicos (CRT), que agrupa las computadoras y recursos adicionales, como un USB con portal educativo o un servidor de $500 \mathrm{gb}$, un ecran y un cañon multimedia. Adicionalmente, y en la idea de diversificar la oferta tecnológica, en esta etapa, se reparte en cada CRT un kit de robótica MindLab, compatible con las XO. 
El programa gubernamental que antecedió a OLPC se denominaba «Proyecto Huascarán» (2001-2006), y tenía una aproximación diferente, en tanto implementaba laboratorios de cómputo a las escuelas, lo cual implicaba la instalación de un conjunto de computadoras PC para el uso compartido junto con el acceso a Internet y el desarrollo de contenidos multimedia. Desde dicho programa, se inició una práctica que aún continúa, como es la implementación y el desarrollo de Aulas de Innovación Pedagógica (en adelante AIP), a cargo de un docente especializado (DAIP), en las cuales se desarrollan actividades educativas con apoyo de TIC. Asimismo, en los últimos años, encontramos el desarrollo del portal PeruEduca, con contenidos para docentes y alumnos, que ofrece recursos adicionales vía conexión a Internet o servidor dedicado.

Paralelamente a estos programas que son gestionados desde el Gobierno Central, y a partir de los procesos de descentralización, los gobiernos locales y regionales han contribuido también a dotar de equipos TIC a las escuelas. Las propias comunidades educativas han jugado un rol significativo en este proceso, tanto en la adquisición como renovación de sus equipos. Este estudio, entonces, contempla el uso de todos estos recursos; no pretende evaluar un programa u otro, sino comprender cómo las TIC son usadas por niños y jóvenes.

\section{Metodología y participantes de la investigación}

El estudio emplea una metodología cualitativa, que permite indagar por las experiencias y percepciones de los actores educativos frente al acceso, uso y apropiación de las tecnologías, y las posibles formas de garantizar su sostenibilidad en el espacio educativo. Las técnicas utilizadas fueron entrevistas semiestructuradas, observación participante, dinámicas participativas con el uso de juegos, fotos, dibujos y video, así como fichas más estructuradas para identificar la disponibilidad y uso de las tecnologías.

En este artículo, nos concentraremos en dos dimensiones del análisis: el acceso y uso de la tecnología educativa, y la percepción de los usuarios en torno a la misma. Para ello, analizamos las fichas de cada escuela y comunidad, entrevistas a docentes (DAIP o coordinadores de CRT), así como las observaciones de aula de las sesiones que empleaban TIC y observaciones de uso de TIC en tiempo libre. Asimismo, entre las técnicas desarrolladas con el alumnado, consideramos principalmente las fotografías producidas por los estudiantes de primaria y los videos producidos por los jóvenes estudiantes de secundaria. Ambas son producto de las dinámicas participativas denominadas «discusión de fotos y videoreportaje». La primera dinámica consistió en dotar a los participantes de cámaras fotográficas para que registren las TIC que conocen y usan en su vida cotidiana. A partir de las fotografías, se pudo discutir sobre las mismas de manera individual. En cuanto a la segunda, se trabaja de modo colectivo: un grupo de estudiantes realiza un reportaje en video vinculado con la temática del uso de las TIC por parte de los jóvenes de su entorno. Los estu150 I diantes elaboran colectivamente el guión de un reportaje o de una historia de 
ficción, hacen las grabaciones en video y las editan usando el programa Movie Maker, todo ello con el apoyo de un facilitador.

En total, participaron del estudio 69 niños, niñas y adolescentes, 13 docentes, 10 directores y subdirectores y 5 funcionarios de las Unidades de Gestión Educativa Local (UGEL), así como 9 pobladores (autoridades o representantes locales), provenientes de La Libertad, Puno y Ucayali. En cada región, se trabajó tanto en ámbitos urbanos como rurales y en primaria ( $5^{\circ}$ grado) y secundaria ( $3^{\circ}$ año). Todas las escuelas eran polidocentes completas, excepto en la zona rural de Ucayali, donde la primaria era multigrado. El principal criterio de selección fue la presencia de TIC en las escuelas y un uso frecuente (al menos semanal) de las mismas. En la tabla I, presentamos las principales características de cada localidad ${ }^{5}$.

Tabla I. Características de las localidades estudiadas

\begin{tabular}{|c|c|c|c|c|c|c|}
\hline Región & \multicolumn{2}{|c|}{ La Libertad } & \multicolumn{2}{|c|}{ Puno } & \multicolumn{2}{|c|}{ Ucayali } \\
\hline Localidad & Trujillo & Virú & Puno & Huancané & Pucallpa & Padre Abad \\
\hline Área & Urbana & Rural & Urbana & Rural & Urbana & Rural \\
\hline $\begin{array}{l}\text { Altura } \\
(\mathrm{msnm})\end{array}$ & 34 & 164 & 3850 & 3824 & 164 & 250 \\
\hline Población & 783.283 & 820 familias & 139.816 & 300 familias & 270.780 & 120 familias \\
\hline $\begin{array}{l}\text { Principales } \\
\text { actividades } \\
\text { económicas }\end{array}$ & $\begin{array}{l}\text { Turismo } \\
\text { Industria } \\
\text { Servicios }\end{array}$ & $\begin{array}{l}\text { Agroindustria- } \\
\text { exportación } \\
\text { Agricultura } \\
\text { Pesca artesanal }\end{array}$ & $\begin{array}{c}\text { Servicios } \\
\text { Comercio } \\
\text { Turismo }\end{array}$ & $\begin{array}{c}\text { Ganadería } \\
\text { Producción } \\
\text { de leche y } \\
\text { derivados } \\
\text { (queso, } \\
\text { yogurt) }\end{array}$ & $\begin{array}{l}\text { Servicios } \\
\text { Comercio }\end{array}$ & $\begin{array}{l}\text { Agroindus- } \\
\text { tria (palma } \\
\text { aceitera) } \\
\text { Explotación } \\
\text { forestal } \\
\text { Piscigranjas }\end{array}$ \\
\hline
\end{tabular}

Fuente: Elaboración propia

\section{Principales hallazgos}

\subsection{Acceso: ¿Más TIC fuera que dentro de la escuela?}

Si consideramos que es en las escuelas donde supuestamente se trasmiten los conocimientos valorados por la sociedad, esta constituye necesariamente un lugar privilegiado para acceder al conocimiento y uso de las tecnologías, que son cada vez más una parte importante de nuestra vida cotidiana en aspectos

4 Para seleccionarlas, se empleó la base de datos de la Encuesta Nacional sobre Acceso, Uso, Apropiación y Sostenibilidad de Tecnologías Educativas a Nivel Primaria y Secundaria - Entic (2012).

5 Para proteger la confidencialidad y anonimato de los participantes, la localidad se nombra por la provincia en la que se ubica, y todos los nombres propios han sido reemplazados por seudónimos. 
económicos, sociales, laborales, políticos y culturales. Este razonamiento estaría justamente en la base de los programas que han distribuido equipos en los últimos años. En las escuelas, entonces, deberíamos encontrar un espacio de aprendizaje de las tecnologías, a la par que se aprende con ellas. Sin embargo, los estudiantes no tienen la misma percepción; y es que el acceso físico a las tecnologías en la escuela, muchas veces, es muy restrictivo en comparación con las condiciones de acceso por fuera de ella.

En la medida que la mayor presencia de TIC por fuera de la escuela es una tendencia que se intensifica cada vez más, con la mayor accesibilidad a las TIC en el mercado (abaratamiento de los equipos) y el consumo cada vez más masivo de las mismas, esperábamos encontrar que la distribución de equipos en las escuelas públicas - producida en los últimos años- implicaría cambios importantes en el acceso. En efecto, las escuelas seleccionadas disponían de un paquete tecnológico variado -como se muestra en la tabla II-, que contrasta con la situación apenas una década atrás (Trinidad, 2005).

Tabla II. Tecnologías disponibles en las II.EE. estudiadas

\begin{tabular}{|c|c|c|c|c|c|c|}
\hline Región & \multicolumn{2}{|c|}{ La Libertad } & \multicolumn{2}{|c|}{ Puno } & \multicolumn{2}{|c|}{ Ucayali } \\
\hline Localidad & Trujillo & Virú & Puno & Huancané & Pucallpa & P. Abad \\
\hline Área & Urbana & Rural & Urbana & Rural & Urbana & Rural \\
\hline XO Primaria & 39 & 20 & 15 & 20 & 36 & 16 \\
\hline XO Secundaria & 29 & 22 & 27 & 30 & 11 & 14 \\
\hline KIT ROB. & 12 & 6 & 2 & 4 & 6 & 2 \\
\hline PC Prim. & 15 & 2 & 12 & 23 & 35 & 4 \\
\hline PC Secund. & 20 & 2 & 12 & $2 J$ & נJ & 4 \\
\hline Ecran & 2 & 1 & 5 & 1 & 2 & \\
\hline Proyector & 3 & 1 & 1 & 1 & 2 & \\
\hline TV & 5 & 1 & 3 & 3 & 4 & \\
\hline DVD & 5 & 1 & 1 & & 1 & \\
\hline $\begin{array}{l}\text { Equipo de } \\
\text { sonido }\end{array}$ & $\begin{array}{l}1 \text { Radio } \\
\text { portátil }\end{array}$ & $\begin{array}{l}1 \text { Mini } \\
\text { compo- } \\
\text { nente }\end{array}$ & $\begin{array}{l}1 \text { Radio } \\
\text { portátil }\end{array}$ & $\begin{array}{l}1 \text { Equipo } \\
\text { de sonido }\end{array}$ & $\begin{array}{l}1 \text { Equipo } \\
\text { de sonido }\end{array}$ & $\begin{array}{l}1 \text { Equipo } \\
\text { de sonido }\end{array}$ \\
\hline $\begin{array}{l}\text { Internet } \\
\text { (operativo) }\end{array}$ & No & $\mathrm{Si}$ & $\begin{array}{l}\text { Sí (solo } \\
\text { prima- } \\
\text { ria) }\end{array}$ & Sí & No & No \\
\hline Alumnado total & 1028 & 243 & 372 & 336 & 1182 & 241 \\
\hline
\end{tabular}

Fuente: Elaboración propia 
A pesar de esta mayor dotación de equipos, lo que encontramos es que, en la mayoría de los casos, el acceso a tecnologías por fuera de la escuela sigue siendo -en términos generales- más amplio que dentro de ella. Incluso en aquellos hogares considerados de sectores populares, encontramos que niños y adolescentes disponen de una variedad de tecnologías que supera muchas veces la disponible en la escuela: televisores de pantalla plana y con conexión a cable, DVD, celulares de última generación, laptops, PC, tableta, mp3, consolas de videojuegos y juegos online, etc. Solo la expansión de los smartphones con conexión a Internet ha supuesto una radical transformación del acceso a este recurso (Internet), que ha conducido a la desaparición de las cabinas en algunos sectores, como pudimos comprobar en los barrios de Trujillo y Puno que visitamos. La escuela, por lo tanto, tiene que bregar por estar a la par y mantenerse al mismo nivel que se observa fuera de ella, en cuanto al acceso y uso de tecnologías, una tendencia que es común a muchos países (Pedró, 2012). ¿Por qué hacerlo si hay más TIC fuera de la escuela? Una primera razón tiene que ver con que la presencia de las TIC por fuera de la escuela no garantiza su uso para fines educativos o para favorecer el desarrollo de aprendizajes escolares. Una segunda se vincula con la heterogénea y desigual distribución de equipos. Abordemos, primero, esta mayor presencia de las TIC en los hogares, para desarrollar después este último punto.

Este mayor acceso fue especialmente notorio en Trujillo, Puno y Huancané, donde las fotografías que los niños hicieron a sus equipos nos mostraron una considerable variedad y un acceso a computadoras personales, Internet y celular bastante difundido, que incluía tanto los equipos disponibles en el propio hogar como en hogares vecinos de parientes cercanos. En Trujillo, por ejemplo, todos los adolescentes participantes del estudio tenían celulares de última generación (smartphones) y acceso a Internet; y todos, menos uno, tenían una PC o laptop en casa. En Virú, una zona rural agrícola en la misma región, por el contrario, el acceso a nivel de cada hogar es más limitado, y la variedad y capacidad de los equipos más restringida. Solo dos de los seis adolescentes participantes tenían smartphones, y otro un celular no Smart. A ello se debe agregar que solo uno tenía acceso a PC e Internet en casa. Existen, sin embargo, espacios públicos - como cabinas-, donde pueden acceder a computadoras e Internet. Fue en Ucayali, tanto en zona urbana (Pucallpa) como rural (Padre Abad), donde encontramos un menor acceso a tecnologías en el hogar: solo un hogar entre los doce visitados en Pucallpa contaba con PC, y ni adolescentes ni niños tenían dispositivos propios, aunque sí disponían de cabinas públicas en el barrio. En Padre Abad, todos los adolescentes tenían celulares, y tres hogares de diez visitados contaban con PC (uno con Internet).

El acceso a tecnologías en los hogares no es, pues, homogéneo, y niños y jóvenes muestran diferentes grados de acceso tanto entre las distintas regiones como dentro de ellas, e incluso al interior de cada escuela. En efecto, en cada escuela, podíamos encontrar dentro del grupo que, si bien todos conocían la existencia de gran variedad de tecnologías, no todos tenían acceso 
en la misma medida. En Puno, por ejemplo, un niño podía tener acceso a PC, Internet y tablet, mientras otros dos de su mismo salón no tenían acceso directo a ninguno de ellos. En general, los adolescentes en cada región, estudiantes de secundaria, mostraban un mayor acceso a dispositivos personales como celulares y USB que los niños de primaria. Entre las zonas urbanas y rurales, encontramos también diferencias, algunas veces contra intuitivas: así, lo esperable era encontrar cierta brecha entre la ciudad y el campo, con un mayor acceso en la primera en comparación con el segundo. Esto se verificaba en La Libertad, como ya hemos visto, donde los niños y jóvenes de la zona urbana de Trujillo tenían acceso a tecnología variada, diversos dispositivos y de última generación; mientras, en la zona rural, si bien el acceso a tecnología existía, en muchos casos, se trataba de versiones más antiguas, menos rápidas y -asimismo- estaba presente en menor cantidad de casos. En Puno, sin embargo, el acceso en la zona rural era muy similar al acceso en la zona urbana estudiada, sobre todo entre los niños de primaria. En gran medida, ello se debe a que se trataba de una zona rural de propietarios ganaderos de mejor posición económica y con acceso a una ciudad con amplia oferta de tecnologías. No obstante, entre los adolescentes, sí podía notarse un acceso más directo a los equipos y más variado en la ciudad capital. En Ucayali, como ya mencionamos, el acceso a equipos era el más limitado, y los adolescentes del campo disponían de celulares en mayor medida que los de la ciudad; quizás, por tratarse de un barrio pobre de la misma. En términos generales, sin embargo, podríamos decir que en conjunto había más acceso y se usaban más los equipos disponibles fuera que dentro de la escuela.

Llegado a este punto, es necesario acotar que la existencia de los equipos físicamente disponibles en la escuela no garantiza que los estudiantes tengan acceso a ellos. En algunas escuelas en las que trabajamos, los estudiantes de todos los grados tenían acceso a las tecnologías educativas disponibles (la escuela primaria de Huancané, por ejemplo, o ambos niveles en Trujillo), pero, en otras, las salas de computación o las XO no estaban disponibles para todos los grados. En efecto, en ciertos casos, eran solo algunos grados de secundaria los que tenían acceso (como en Pucallpa o en la secundaria de Puno); y, en otros, la inadecuación de la infraestructura o la falta de un DAIP conducía a que ningún grado tuviera acceso a los equipos (como en Virú o en la primaria de Puno, respectivamente). En esa medida, aunque nos guiamos por lo reportado en la Entic para seleccionar las escuelas, no siempre encontramos un acceso óptimo a las tecnologías educativas disponibles en ellas. Adicionalmente, hay que considerar que, si bien todas las escuelas habían recibido las computadoras $\mathrm{XO}$, ninguna de ellas la recibió en la primera etapa -cuando era efectivamente una computadora por niño-, sino en la segunda -cuando era un paquete de computadoras para toda la escuela de uso compartido-. En la actualidad, ninguno de los alumnos de las escuelas estudiadas puede llevarse una computadora a su casa, o sacarla del aula en la que se utiliza y almacena, como solía ser 154 I presentado en la publicidad del programa. 
Asimismo, encontramos que las horas de acceso a las computadoras (sean $\mathrm{XO}$ o PC) eran limitadas, así como las actividades que se podían realizar en esas salas. En Trujillo, por ejemplo, el reglamento del AIP estipula que los alumnos «deberán trabajar solo en la actividad que el docente ha señalado». De este modo, se corta cualquier posibilidad de indagación y exploración propia. Asimismo, al indicar que «trabajaran en orden y en silencio para escuchar las orientaciones de sus profesores», limitan la posibilidad de trabajo entre pares y aprendizaje colaborativo que muchas veces surge de manera espontánea entre niños y jóvenes.

Todo ello contrasta con un acceso mucho más libre y menos restringido que tienen los alumnos por fuera de la escuela: las cabinas de Internet -por ejemplo-, donde las actividades dependen más del usuario que de un instructor, donde las horas de acceso son reguladas por el propio usuario (y su disponibilidad de recursos), y donde los incentivos para el uso, la indagación y la exploración suelen ser mayores que las restricciones. Otro ejemplo, más para el caso de los adolescentes, son los smartphones, en el cual nuevamente el usuario regula, explora, usa e indaga con mayor libertad que la que se le permite en la escuela. Es cierto, también, que la utilización de las tecnologías por fuera de la escuela tiene más fines recreativos que educativos, como veremos al observar el uso, pero aquí queremos destacar el acceso a las tecnologías mismas.

Cabe anotar que reconocemos que el acceso en las cabinas o a los smartphones no es necesariamente igual para todos. En el primer caso, pudimos observar que es un espacio mucho más permitido a los chicos que a las chicas en ciertos barrios (Trujillo, Pucallpa), en tanto se ve como un espacio más masculino (y es -en efecto- más frecuentado por varones, jóvenes y adultos) ${ }^{6}$; tampoco, existe en algunas zonas rurales (Huancané, Padre Abad). La escuela entonces tendría un importante rol que cumplir para nivelar el acceso tanto de varones como de mujeres a estas tecnologías.

En cuanto al segundo caso, el acceso a celulares inteligentes, que está más presente en los adolescentes -no tanto así en los niños entrevistados (aunque tienen acceso a los de sus padres y hermanos para juegos, fotos y otras funciones recreativas)-, está obviamente condicionado por la capacidad adquisitiva. El rol de la escuela en la nivelación de las disparidades que se generan entre distintos sectores socioeconómicos - a partir del ofrecimiento de un acceso equitativo a todos más allá de su origen social- se hace nuevamente aparente. Sin embargo, este rol no logra cumplirse a cabalidad en algunos casos, a pesar de que el fuerte impulso recibido en la distribución de equipos en los últimos años buscaría aminorar justamente estas disparidades. Es notorio, por ejemplo, que es justamente en los lugares en los que más podría compensar disparidades en el acceso -como las zonas rurales, o la región amazónica- donde notamos justamente un menor acceso y uso de las TIC en la escuela, de modo que más que superarse se refuerzan las brechas (excepto en el caso de Huancané). En la 
tabla III, se resume la información sobre acceso por localidad, que permite ver cómo no todos los estudiantes tienen garantizado el acceso a las TIC disponibles en la escuela (presentadas en la tabla II).

Tabla III. Acceso a TIC por localidad y nivel

\begin{tabular}{lcccccc|}
\hline \multicolumn{1}{c}{ Localidad } & Trujillo & Virú & Puno & Huancané & Pucallpa & P. Abad \\
\hline Área & Urbana & Rural & Urbana & Rural & Urbana & Rural \\
\hline $\begin{array}{l}\text { Acceso a } \\
\text { TIC }\end{array}$ & & & & & & \\
Primaria & Sí & No & No & Sí & No & No \\
Secundaria & Sí & No & Sí & Sí & Sí, $4^{\circ}$ y $5^{\circ}$ & No \\
$\begin{array}{l}\text { Frecuencia } \\
\text { de uso }\end{array}$ & $2 \mathrm{~h} . \mathrm{r} /$ & 0 & $\begin{array}{c}0(\mathrm{P}) \\
2 \mathrm{hr} / \mathrm{sem} .\end{array}$ & $2 \mathrm{hr} / \mathrm{sem}$. & $0(\mathrm{P})$ & 0 \\
\hline
\end{tabular}

Fuente: Elaboración propia

En este punto, es necesario abordar lo que podríamos llamar un «acceso precario» a las tecnologías educativas que hemos encontrando en el estudio. En efecto, si tomamos la acepción que nos ofrece la Real Academia de la Lengua para esta palabra -«De poca estabilidad o duración», encontramos que efectivamente puede aplicarse al acceso a las tecnologías en algunos de los casos estudiados. El caso paradigmático es el de la primaria de Puno, en la cual -a pesar de contar con un CRT y un AIP, es decir con un paquete tecnológico básico y un espacio destinado a albergarlo- el mismo no es accesible a los niños y niñas, debido a que se carece de un docente capacitado. En los años previos (2012 y 2013), se contaba con una DAIP y los niños usaban el AIP dos horas a la semana; y, eventualmente (una vez al mes), el kit de robótica. Debido al traslado de esta docente y la ausencia de un reemplazo, nadie usa los equipos actualmente. Ello muestra que los docentes regulares no integraron las tecnologías a su trabajo pedagógico (solo dejaban a los alumnos en el AIP y los recogían dos horas después), lo cual muestra el limitado impacto de las tecnologías en esta escuela en general. Hay, evidentemente, una gran dependencia en esta escuela de una persona que «sepa»; y, si no hay, no se usa la tecnología. Ninguno de los 17 docentes de primaria solicita las XO o busca cómo emplear el AIP para sus cursos, aparentemente, por falta de conocimiento o capacitación.

No es ese el caso en las otras escuelas primarias, como las de Trujillo y Huancané, en las cuales los docentes de aula trabajan conjuntamente con el DAIP cuando van al AIP o al espacio de CRT. Estas escuelas nos muestran, más bien, que sí es posible involucrar a la comunidad educativa de manera general. Todos participan y hacen uso de las tecnologías, unos más que otros, pero todos en alguna medida. En este caso, dos figuras resultan importantes como dinamizadores de este acceso generalizado: el o la DAIP, y el o la directora(a) del nivel. En 
el primer caso, se trata de la persona que orienta a sus colegas, ofrece materiales complementarios o resuelve problemas técnicos que el docente regular no puede resolver. En el segundo caso, es evidente la importancia de una gestión orientada a promover el equipamiento y uso de las tecnologías. Cuando ambos elementos están presentes, encontramos una mayor estabilidad en el acceso y uso de las tecnologías, pues se logra involucrar al colectivo en ello, y la dependencia de una persona es menor. Es decir, las tecnologías logran ser integradas a la práctica social cotidiana y general de la escuela. También, es necesario señalar que ambas escuelas poseen una infraestructura adecuada y una ubicación que les permite un diálogo constante con las autoridades educativas; ambos elementos coadyuvan a la gestión y no siempre están presentes en las otras escuelas visitadas.

En efecto, otro caso que muestra la precariedad en el acceso -esta vez, por causa de la infraestructura- es el de Virú. Debido a que no cuenta con un espacio adecuado - por la demolición de las aulas antiguas (a punto de colapsar)-, los equipos no están siendo utilizados. Del mismo modo, en Padre Abad, un mal almacenamiento ocasionó que la última inundación deteriore los equipos, por lo que actualmente estos no se usan. En ambos casos, se trata de zonas rurales que se encuentran a cierta distancia de las capitales regionales, lo cual dificulta las gestiones para resolver sus problemas de infraestructura.

Finalmente, es necesario señalar que el temor a que se dañen las computadoras limita su acceso y uso en el tiempo libre de los niños y adolescentes: estos no pueden acceder a ellas ni en el recreo ni en horas libres. Si no hay un docente a cargo, los niños no pueden acceder a las TIC. Esta restricción estaba presente tanto en primaria como en secundaria y en todas las escuelas estudiadas.

En resumen, podemos ver claramente que una mayor disponibilidad de equipos, si bien es necesaria, no resulta suficiente para garantizar un adecuado acceso a los mismos. La presencia física de los equipos es gestionada, organizada y regulada por actores específicos (directivos, docentes) que permiten un mayor o menor acceso a los estudiantes. En la mayoría de los casos, la presencia de los equipos es integrada a las prácticas sociales escolares existentes, a la lógica de funcionamiento de la institución y el acceso es limitado y puntual. Ello contrasta con la creciente oferta TIC por fuera de la escuela, en el espacio del hogar o de la comunidad. Esta tendencia a la integración de las TIC a las prácticas escolares existentes se visibiliza mejor cuando abordamos el uso de las TIC, como lo haremos a continuación.

\subsection{Un uso todavía limitado}

\section{En la escuela}

Los estudiantes demandan tanto aprender sobre las TIC, como aprender con ellas y a través de ellas, en tanto les resultan atractivas. Esta demanda constituye una gran oportunidad para la escuela, que no siempre es aprovechada. En efecto, los estudiantes, tanto niños como adolescentes, señalaron que les agrada cuando 
sus profesores hacen uso del AIP o el CRT para sus clases, que disfrutan viendo videos o utilizando las $\mathrm{XO}$ o las $\mathrm{PC}$ en el marco de sus cursos (con una clara preferencia por las últimas, en relación con las primeras -como explicaremos más adelante-). Sin embargo, en las clases que observamos, pudimos notar que en el $90 \%$ de los casos el uso de las tecnologías no aprovecha plenamente su potencial, en tanto se desarrollan actividades que podrían también realizarse sin ellas. Es decir, las TIC son utilizadas como extensión del cuaderno o la pizarra, y rara vez involucran habilidades digitales más complejas. El siguiente extracto de una observación de aula ilustra lo expuesto:

La profesora anuncia que verán un cuento. Los niños giran sus sillas en dirección a la pizarra y al televisor y empieza la proyección del vídeo. Los niños están bastante atentos al cuento, que lleva por título «El zapatero y el duende». Los personajes son una suerte de dibujo animado y marionetas, lo cual lo hace especialmente atractivo. La proyección dura cerca de 10 minutos y al terminar la profesora pasa adelante y les pregunta a todos: «iLes ha gustado?». Los niños le responden que sí. La profesora hace preguntas sobre el cuento, sobre el tema, sobre el personaje principal, sobre el mensaje del cuento y los valores que encuentran en él; los niños levantan la mano, casi todos quieren responder; $y$, cuando la profesora nombra alguno, este responde. Tras cinco minutos de preguntas, se pasa a una lluvia de ideas en torno a estos temas que la profesora va copiando en la pizarra en tanto las va escuchando. Tras diez minutos en esta suerte de lluvia de ideas, la profesora toma un plumón y escribe en la pizarra acrílica «El cuento» como título, y les dice a los alumnos «Ustedes me van a ayudar a hacer la clase». Les consulta, entonces, por las partes del cuento, los niños levantan la mano y participan, se muestran bastante participativos. Así, con ayuda de los niños, arma un mapa conceptual sobre las partes del cuento en la pizarra y al terminar dice a sus alumnos « $\mathrm{Va}$ mos a intentar que ustedes hagan lo de la pizarra en las $X O{ }^{7}$, los niños encienden de inmediato las XO e intentan copiar el mapa conceptual (Extracto de Observación de Aula, $5^{\circ}$ grado, Trujillo).

Este extracto expresa una tendencia bastante presente en las aulas: acomodar el recurso tecnológico como extensión del libro (ver un video en vez de leer un libro) o del cuaderno (copiar de la pizarra en la XO). Si bien es cierto que la $\mathrm{XO}$ se ha planteado como un recurso que puede reemplazar al cuaderno y ampliar la oferta de libros disponibles con los digitales, también, ofrece un acceso a otra forma de construcción de conocimientos con la participación más activa del estudiante. Sin embargo, no vemos que ello se aproveche en este ejemplo (ver Papert, citado por Warschauer y Ames, 2010, p. 35). 
La mayor parte de lo que sigue en esta clase se dedica a resolver problemas prácticos del manejo de la XO (cómo hacer los cuadros, flechas y diagramas), y se deja de lado el tema de la sesión (¿el cuento? ¿las partes del cuento?). Al final de la clase, la profesora intenta que los niños tomen foto (con la XO) a unas imágenes y las incorporen al mapa conceptual, de modo que se añade una dimensión multimedia a la actividad. Sin embargo, el tiempo les ha ganado y solo tres niños logran hacerlo. Esta última actividad es lo más cerca que encontramos de un uso más propio de las posibilidades de las TIC (trabajo multimedia), aunque también encontramos paralelos con el cuaderno (pegar una foto para ilustrar el trabajo).

Aprender a usar la XO no es un objetivo desdeñable; sin embargo, en la medida que se trata de estudiantes de $5^{\circ}$ grado, esperaríamos que tuvieran ya un mayor dominio de la misma. En todo caso, se aprecia que la clase se desvía del tema propuesto para concentrarse en el manejo de la tecnología. Más importante aún, el planteamiento pedagógico de la clase no parece verse afectado o transformado por la presencia de la tecnología. Con todo, el ejemplo propuesto nos muestra uno de los usos que más incorpora recursos tecnológicos. Los usos de las TIC que hemos observado al interior de la escuela y con/por los estudiantes se resumen en la tabla IV:

Tabla IV. Usos observados sg. nivel primaria $(\mathrm{P})$ y secundaria $(\mathrm{S})^{8}$

\begin{tabular}{|c|c|c|c|c|}
\hline Usos observados & Trujillo & Virú & Puno & Huancané \\
\hline $\begin{array}{l}\text { 1. Observar un video con un cuento o documental, } \\
\text { que ofrezca información o motivación (uso de pro- } \\
\text { yector y ecran o TV) }\end{array}$ & $\mathrm{P}$ & $\mathrm{S}$ & S & S \\
\hline $\begin{array}{l}\text { 2. Leer textos digitales -cuentos o diapositivas infor- } \\
\text { mativas (XO) }\end{array}$ & & & & $\mathrm{P}$ \\
\hline 3. Hacer un mapa conceptual (XO) & PS & & & \\
\hline $\begin{array}{l}\text { 4. Resumir oralmente un cuento (proyectado en } \\
\text { ecran o leído en la computadora) }\end{array}$ & & & & $\mathrm{P}$ \\
\hline 5. Escribir palabras $(\mathrm{XO})$ & & $\mathrm{P}$ & & \\
\hline $\begin{array}{l}\text { 6. Observar o leer presentación-PPT o Powtoon } \\
\text { (PC, ecran) }\end{array}$ & & S & $S$ & S \\
\hline 7. Manejar una hoja de cálculo - Excel & & & & S \\
\hline 8. Conocer partes de la máquina, diagnóstico (PC) & & & S & \\
\hline $\begin{array}{l}\text { 9. Escuchar música y cantar (radio, equipo de soni- } \\
\text { do) }\end{array}$ & $S$ & & & \\
\hline 10. Inventario del kit de robótica (kit) & & & & $\mathrm{P}$ \\
\hline 11. Juegos de palabras (del Portal PeruEduca) (XO) & & & & $\mathrm{P}$ \\
\hline 12. Armar rombecabezas (XO o $\mathrm{PC})$ & & & & $\mathrm{P}$ \\
\hline 13. Colorear dibujos (PC) & & & & $\mathrm{P}$ \\
\hline
\end{tabular}

Fuente: Elaboración propia

8 No se incluye Ucayali, donde no se realizaron sesiones con TIC o no pudieron observarse. 
Con excepción del uso audiovisual, extendido en todas las escuelas observadas y de uso tanto en primaria como en secundaria, los primeros 5 de la lista (2-6) involucraban acciones que podrían haberse hecho con libros, lápiz y papel. En la elaboración del mapa conceptual, como hemos visto en el caso expuesto, los docentes al final de la sesión enseñaban a los niños a tomar e incluir fotografías, de modo que se introducía un elemento multimedia en la actividad. No obstante, rara vez hemos podido observar que la actividad solicitada involucre acciones que solo las funciones de la tecnología podrían cubrir, como este último ejemplo. Lapeyre (2014) menciona diversas estrategias pedagógicas posibles para las TIC en el aula, que contrastan con la extensión del cuaderno y el libro que verificamos en los ejemplos anteriores. Estas incluyen la producción de formatos y objetos virtuales (creación de procedimientos, diseño de espacios virtuales, modelización, recorridos virtuales), el trabajo colaborativo virtual (interacción en espacios virtuales), y la indagación interactiva (mapeo de información, creación de portafolios virtuales, curación de contenidos), usos que no hemos encontrado en las escuelas estudiadas.

En los casos 7 y 8 , se trata de un uso que solo puede darse con la tecnología, pero que se queda en el conocimiento básico de partes y procedimientos. Ello, además, se observa básicamente en secundaria, lo cual refleja la concepción tradicional del curso de computación. Los usos 10 al 13 solo están presentes en primaria y son los únicos que contienen elementos lúdicos, de modo que se evidencia la ausencia de los mismos en las sesiones destinadas para secundaria. Cabe anotar que los juegos y audiovisuales son los favoritos de los estudiantes. Los últimos dos se usan con los más pequeños para ayudar al manejo inicial de los equipos (mouse, pad, teclado). La mayor diversidad de usos identificados corresponde a la escuela rural de Huancané, en la cual pudimos realizar más observaciones gracias a un uso más frecuente de las TIC y mayor disponibilidad para el ingreso a las aulas.

Es necesario recalcar, asimismo, que el uso de los equipos es poco frecuente. Como se indica en la tabla II, solo dos de las seis escuelas usan algún tipo de TIC (que incluye o bien PC o bien XO) dos horas semanales en ambos niveles, mientras que en otras dos esto solo sucede en el nivel secundario; y, en otras dos, se usan las TIC de modo muy restringido a pesar de tener equipos disponibles. Esperábamos una mayor frecuencia de uso de las TIC -especialmente, de las XO-, dado que estas ya llevan algún tiempo en las escuelas, de manera que podrían haberse instalado más y mejor en la práctica pedagógica. Sin embargo, como otros estudios han señalado, no es inusual encontrar un descenso en el uso de las XO con el tiempo (Santiago et ál., 2010), en gran medida por problemas con su funcionamiento y deterioro en el primer o segundo año de uso (Warshauer y Ames 2010).

Con respecto al uso de las $\mathrm{XO}$, un hallazgo significativo fue que para niños y jóvenes estas constituían las tecnologías menos atractivas. En efecto, cuando en las dinámicas de trabajo grupal les pedíamos ordenar las diversas tecno160 I logías que conocían y usaban según la importancia que tenían para ellos, las 
$\mathrm{XO}$ con frecuencia aparecían en el último o penúltimo lugar. Este hallazgo que puede parecer paradójico -dado que las XO están destinadas y diseñadas especialmente para el uso personal de niños y jóvenes-, no lo era cuando indagábamos más al respecto y observábamos el contexto de uso de las $\mathrm{XO}$ y de otras tecnologías con las que eran comparadas.

Para empezar, las XO funcionan con un software propio, basado en el sistema operativo Linux y una interface gráfica (Sugar). Este es diferente del comúnmente disponible en el mercado peruano, el Windows, con el cual los niños estaban más familiarizados, debido a su uso en el mundo exterior a la escuela. Así, en comparación con la PC o laptop que podían utilizar en casa o en la cabina pública, la XO aparecía como una computadora no del todo «verdadera», y cuyo uso estaba circunscrito a la escuela, puesto que no circula en el mercado y no pueden llevarla a casa (Villanueva y Olivera, 2012, reportan una percepción similar). Para dificultar las cosas, con frecuencia, las XO no tenían acceso a Internet, mientras que las PC a las que acceden los niños y adolescentes fuera de la escuela con frecuencia lo tienen, así como sus teléfonos celulares, en el caso de los adolescentes (que por cierto ocupaban el primer lugar en el ranking de preferencias entre ellos). Adicionalmente, para los adolescentes y niños mayores, el pequeño teclado y pantalla de las XO podía ser algo incómodo. Además, la poca duración de su batería hacía que generalmente tuvieran usarlas enchufadas y, por lo tanto, con movilidad limitada, es decir, en la mesa del AIP o CRT. Recordemos también que, en estas escuelas, las XO no podían salir de la escuela ni incluso de los salones en los que eran almacenadas (AIP o CRT). Todo ello parece indicarnos que la XO se había convertido en un artefacto escolar, cuyo uso y relevancia se daba únicamente en dicho espacio, y no era por tanto significativa en la vida cotidiana de los niños por fuera y más allá de la escuela. Parafraseando a Street y Street (2004), asistimos a la «escolarización» de la XO, que paradójicamente proponía desescolarizar el aprendizaje (Warschauer y Ames, 2010, p. 34).

Pese a estar en un bajo lugar en el ranking, los estudiantes de primaria identificaban algunos programas favoritos en las $\mathrm{XO}$, como eran los juegos educativos (Sara habla, Rompecabezas). Sin embargo, más allá de estos, eran pocas las menciones a otros programas utilizados en la misma (por lo general, el procesador de textos, calculadora, organizadores, fotografía y video), debido a que también su uso era poco frecuente. Esto es consistente con los hallazgos de Cristia et ál. (2012, p. 3), quienes -al revisar los logs de las XO en las escuelas que estudiaron- encontraron que una parte sustantiva del uso de la XP se dirigía a este tipo de actividades (juegos procesador de textos, calculadora, música, grabación de audio y video).

\section{Fuera de la escuela}

Los usos reportados y observados por los estudiantes fuera de la escuela, como veremos, contrastan con los observados en la escuela. Son típicamente los siguientes: 
Tabla V. Usos observados fuera de la escuela, nivel primaria (P) y secundaria (S)

\begin{tabular}{ll}
\hline \multicolumn{1}{c}{ Niños (Primaria) } & \multicolumn{1}{c}{ Adolescentes (Secundaria) } \\
\hline $\begin{array}{l}\text { Ver televisión (dibujos animados, } \\
\text { programas de concurso, películas) }\end{array}$ & $\begin{array}{l}\text { Ver televisión (programas de concursos, } \\
\text { series, novelas, películas) }\end{array}$ \\
$\begin{array}{l}\text { Escuchar y bajar música, ver videos } \\
\text { musicales (YouTube, PC y dispositivos } \\
\text { personales) }\end{array}$ & $\begin{array}{l}\text { Escuchar y bajar música, ver videos } \\
\text { musicales (YouTube, PC y dispositivos } \\
\text { personales) }\end{array}$ \\
Jugar videojuegos (en tablet, laptop o PC) & $\begin{array}{l}\text { Jugar videojuegos (en tablet, laptop o PC) } \\
\text { Chatear y postear en redes sociales, para } \\
\text { comunicarse con amigos, para pasarse } \\
\text { información entre compañeros sobre tareas } \\
\text { (Facebook) }\end{array}$ \\
$\begin{array}{ll}\text { Navegar en Internet (Google, YouTube, } \\
\text { juegos online) }\end{array}$ & $\begin{array}{l}\text { Navegar en Internet (Google, YouTube, } \\
\text { juegos online, Facebook) }\end{array}$ \\
& $\begin{array}{l}\text { Descargar imágenes o textos de internet } \\
\text { para imprimir }\end{array}$ \\
$\begin{array}{l}\text { Hacer la tarea (con ayuda de PC o laptop } \\
\text { e Internet) }\end{array}$ & $\begin{array}{l}\text { Hacer la tarea (con ayuda de PC o laptop } \\
\text { e Internet) }\end{array}$ \\
$\begin{array}{l}\text { Hablar por teléfono (fijo o celular) y jugar } \\
\text { en teléfono celular de padres o hermanos, chatear, jugar en teléfono celular } \\
\text { mayores }\end{array}$ & \begin{tabular}{l} 
personal \\
\hline
\end{tabular}
\end{tabular}

Fuente: Elaboración propia

Con frecuencia, niños y jóvenes reportan que varios de estos usos pueden ser simultáneos (ver televisión, jugar en la computadora, escuchar música). Un ejemplo se muestra en la siguiente observación:

Propuse a Alfonso que suponga que tiene que hacer un trabajo sobre el sistema digestivo y sus funciones. Lo primero que hace es conectarse a Internet; luego, ingresa a Google y busca «El aparato digestivo y sus funciones». Ingresa al primer link que aparece, lo revisa. Luego, abre otra ventana y entra a Wikipedia; pone «el aparato digestivo» en la búsqueda, y lee el contenido de la página. Tras unos momentos, abre otra ventana e ingresa a YouTube y pone "La cumbia del Hameha» (rap) y canta. Sigue revisando la información de Wikipedia hasta que la canción ha terminado; regresa a YouTube para poner otra canción de Daddy Yankie. Vuelve a revisar la información de Wikipedia, pero parece aburrido; por momentos, gira el torso para ver si su madre lo está observando. Lee, mientras está escuchando música. Abre un documento de Word. Observa un dibujo del aparato digestivo, lo escoge y lo copia al documento de Word. Copia también la información que ha encontrado en 
Wikipedia y me dice que lo va a imprimir; lo hace y termina su tarea. Le pido, entonces, que ahora haga sus actividades cotidianas, como si yo no estuviera presente. Lo primero que hace es ingresar al Facebook. Revisa las noticias del muro y, luego, carga Dragon City y abre su cuenta de Twitter (tiene 12 seguidores y sigue a 26 personas). En su foto de perfil, aparece con un gorro a lo Daddy Yankie. Me comenta que tiene varias fotos con su familia, porque «soy evangélico». Es, además, hincha de Cristal y del Barcelona de España, y tiene como foto de portada a todo el equipo del Barcelona. Sigue jugando, cantando y escuchando música. Pasa a jugar Criminal Case; «ya he pasado al nivel 4», me indica. Su mamá tiene que salir, así que damos fin a la observación (Observación de tiempo libre, hogar de Alfonso, 9 años, $5^{\circ}$ grado, Trujillo).

Este ejemplo condensa varios de los usos típicamente observados en niños y adolescentes. Predominan, como puede verse en el extracto, usos recreativos y comunicativos como los juegos online, la música, las redes sociales. La actividad «escolar» propuesta por el observador -en el cuadro, hemos llamado «hacer la tarea»-, aunque ficticia, sigue un patrón similar al observado en otros casos de niños y jóvenes cuando realizan esa misma actividad. Fundamentalmente, se usa el buscador más conocido (Google o Wikipedia), y se emplea una búsqueda simple (y corta) según el tema de la tarea. Luego, se procede al copiado y pegado si se va a imprimir la tarea, o a la transcripción de la computadora al cuaderno, como en el siguiente caso:

Jackie está haciendo la tarea del curso de religión. Las dos preguntas a responder son «¿Qué entendemos por Semana Santa?» y «¿Qué es Domingo de Ramos?». Utiliza el buscador Google, en el que pone la pregunta tal y como está. Espera hasta que aparezca todo lo referido a la Semana Santa. Después, va abriendo cada página hasta que encuentra algo corto y que tenga las palabras de la pregunta introducida. Hay páginas que se demoran en abrir y otras que son muy largas. Estas son rechazadas por Jackie. Ella busca contenidos cortos y que tengan en su redacción las palabras introducidas en el buscador. Si encuentra estas dos características, se queda con él y lo copia a su cuaderno tal y como aparece [...] Después, de hacer la tarea, se puso a escuchar música de String Karma y de Corazón Serrano; pasó unos diez minutos, se aburrió y decidió ingresar al videojuego Friv, al juego Kizzi. Al igual que la música, pasó siete minutos y se aburrió. Luego, se sumó al juego Half life, que ya habían empezado su tío Samuel con uno de sus amigos en otras cabinas (Observación de tiempo libre, cabina pública, Jackie, 9 años, Virú).

El procedimiento observado para hacer las tareas no suele tomar mucho tiempo; y, en comparación con el tiempo destinado a fines recreativos, es me- 
nor: como podemos ver en ambos extractos, se da rápidamente trámite a la tarea para poder ingresar a juegos, redes sociales, música. Las tareas realizadas de este modo reciben altas calificaciones, como nos explicaba Claudio: tras hacer una rápida búsqueda, copiado y pegado, dice que siempre hace sus trabajos así y que los profesores siempre le ponen buena nota: «Me ponen $A{ }^{9}$. Es comprensible que, si los estudiantes reciben buenas calificaciones, esto se convierte en un incentivo para continuar utilizando el mismo procedimiento.

\section{Discusión: Comparando los usos de las TIC}

Si comparamos los usos de la tecnología dentro y fuera de la escuela, salta a la vista que las actividades realizadas en la escuela con ayuda de la tecnología siguen un énfasis bastante secuencial y mantienen una estructura tradicional, que solicita a todos los niños que realicen una misma actividad siguiendo los mismos pasos, indicados por el docente. En ocasiones, hasta se llama la atención de aquellos que avanzan más rápido que el resto:

El DAIP verifica, computadora por computadora, que los estudiantes se encuentran trabajando en el programa de Perú Educa. Los estudiantes que trabajan solos están más adelantados; incluso, han pasado al programa de rompecabezas. Frente a esto, el DAIP les pregunta: «¿Por qué se han pasado a la unidad 2, si todos los demás estaban en la unidad 1?». El docente de aula se muestra nervioso, pero no interviene; los estudiantes tampoco responden. El DAIP agrega: «Deben ir a la par que sus compañeros, ah». Los niños no dicen nada (Observación de aula, $5^{\circ}$ grado, Huancané).

Ello contrasta con las observaciones que hemos realizado en el tiempo libre de los niños, como las reportadas líneas arriba, en las que este control y secuencialidad están ausentes. Niños y adolescentes muestran gran habilidad para trabajar simultáneamente en diversas páginas, realizar múltiples tareas al mismo tiempo, encontrar lo que buscan con rapidez, comunicarse e interactuar en línea. Sin embargo, se debe considerar que ello ocurre, mayormente, en actividades relativas a la recreación (redes sociales, juegos, música). Estas habilidades no se despliegan en el aula, en gran parte, porque se pide explícitamente que no se realicen, como hemos visto en los reglamentos mencionados. Debido a estas restricciones, el observar a los estudiantes en el aula brinda una idea errónea acerca de las reales habilidades de los niños y jóvenes en el manejo de la tecnología, pues por fuera de ella pueden mostrar un mayor y mejor dominio. Veamos, por ejemplo, un extracto de la clase ya presentada sobre el mapa conceptual, en la que participan Alfonso y Claudio: 
La profesora no deja de asistirlos y es que los alumnos siguen preguntado cómo hacer. Alfonso, por ejemplo, ha podido hacer el cuadro del título, pero se ha trabado en cómo mover las flechas y los cuadros. Claudio, por su lado, está avanzando bien; ha hecho el cuadro y no parece tener dificultad mayor. No obstante, lo noto poco entusiasmado mientras va construyendo su mapa conceptual, pues lo hace lentamente, hasta con cierta displicencia, "por cumplir». Tiene una postura de aburrido: apoyando los codos sobre la mesa y con la espalda ligeramente curva va haciendo el cuadro lentamente (Extracto de Observación de Aula, $5^{\circ}$ grado, Trujillo).

En la observación de tiempo libre de Alfonso, consignada líneas arriba, pudimos ver un gran despliegue de habilidades que la observación de esta clase no permite apreciar. Del mismo modo, Claudio impresionó al observador cuando este lo acompañó a la cabina y pudo apreciar su uso simultáneo de dos cuentas de Facebook, Dragon City y YouTube:

«Es impresionante la destreza que muestra con el teclado, anotando una infinidad de claves y combinaciones para obtener más vidas y avanzar en el juego, comparada con la pasividad y apatía demostrada en clase cuando usa una XO» (Observación de tiempo libre, Cabina pública, Claudio, 10 años, $5^{\circ}$ grado, Trujillo).

Existen, claro está, diferencias en el manejo y la habilidad entre niños de un mismo salón; y es notorio que aquellos que tienen un mayor acceso a las tecnologías en el hogar tienen, asimismo, un dominio mayor de las mismas. Los últimos suelen captar mejor las explicaciones del docente y avanzar más en sus trabajos, mientras que los que tienen menos acceso (y son, por lo tanto, quienes más necesitan aprender) quedan relegados. No logran acceder al equipo cuando este es compartido; y, por ello, se distraen y no siguen la explicación, como lo pudimos comprobar en Huancané.

La docente indica dos veces y de manera pausada el procedimiento [ingresar notas y sacar promedios en Excel] ante la atención de todo el salón, indicando que en rojo irían las notas menores a 10,5. Los estudiantes, a pesar de estar atendiendo, se confunden por lo largo del procedimiento que solo se explica oralmente [esto es sin soporte gráfico, ya que no se cuenta con proyector en el aula]. Conversan preguntándose entre ellos y pidiendo una nueva explicación a la docente. Una niña menciona con tono de decepción: «Ay, me perdí». Ante la confusión de la mayoría, la docente decide repetir dos veces más las instrucciones, llamando la atención en voz alta: «Haber, haber, para los que se han retrasado». Sin embargo, en el aula se observa que otros niños no tienen mayores problemas y, por el contrario, están probando en colocar colores alternativos al rojo y azul, propuesto por la docente. La docente pide 
guardar el documento realizado con el nombre «Promedio- estudiantes». Muchos niños preguntan dónde guardar el archivo, mientras unos pocos piden ayuda para poder realizarlo. [...] Se observa que algunos estudiantes avanzan de manera más rápida que otros. Mientras algunos se encuentran ya buscando cómo promediar, otros todavía están en el registro de notas. La docente durante este tiempo recorre el salón observando el trabajo de los estudiantes (Extracto de Observación de aula, $3^{\circ}$ secundaria, Huancané).

Paradójicamente, entonces, en algunos casos, se observa que quien más requiere aprender no logra hacerlo, y quien algo sabe es más bien quien refuerza sus conocimientos y es premiado o reconocido por la escuela. La habilidad tecnológica de la generación más joven no es para nada innata, aunque algunos términos equívocamente parecen sugerirlo, como el acuñado por Prensky (2001): nativos digitales, recientemente criticado por Unwin (2014). Más bien, como lo señalan algunos estudios, el contexto socioeconómico implica también la presencia o ausencia no solo de aparatos, sino también de prácticas alrededor de las tecnologías, que facilitan (o dificultan) su uso en determinadas formas por parte de niños y jóvenes. Tal es el caso del estudio de Benitez Largui y Lemus (2012), que encuentran que los estudiantes de clase media argentinos tienen no solo un mayor acceso que los de sectores populares, sino también una trayectoria más larga con las TIC, una mayor naturalidad en su relación con ellas y mayor variedad en los usos que les dan a las mismas, influenciados por los usos que ven en su contexto inmediato. Así, el capital cultural de cada familia parece seguir jugando un papel central en el manejo de las nuevas tecnologías, como lo hizo en el de las más antiguas.

De otro lado, la habilidad que muchos niños y jóvenes demuestran con la tecnología no les prepara necesariamente para un mayor y mejor aprovechamiento en el procesamiento de la información que requieren como parte de su proceso educativo y desarrollo cognitivo. Por el contrario, los ejemplos de uso fuera de la escuela con fines educativos -como los que consignamos de Alfonso y Jackie- muestran que este es todavía bastante limitado: se trata de búsquedas simples, sin contraste ni validación de la información, del copiado y pegado literal, sin procesar, contrastar, verificar ni resumir la información. Lejos de empoderarlos, a través del acceso a un mayor y mejor conocimiento, esta forma de usar la tecnología parece más bien alienarlos del conocimiento y su producción, al reproducir un patrón tradicional (el copiado) pero a una velocidad menor, y con limitados efectos en sus aprendizajes reales. En este sentido, la necesidad de una adecuada orientación pedagógica es fundamental para aprovechar las ventajas de la tecnología y no un obstáculo, aunque los docentes sean percibidos desde algunas posturas como dispensables (ver, por ejemplo, Negroponte, 2007, citado en Kraemer et ál., 2009, p. 70).

Existe, en abstracto, una generalizada visión positiva con respecto a la tec166 I nología y poca conciencia de sus potenciales efectos perjudiciales o limitantes. 
Los niños de primaria revelaron, por ejemplo, una mirada hasta cierto punto cándida con respecto a la tecnología, cierta fe ciega en la misma. El mejor ejemplo lo constituye el grupo de Huancané, que diseñó el prototipo de un «Doctor Robot» en el marco de una dinámica participativa que formaba parte del estudio. La dinámica consistía en proponerles la creación colectiva de un prototipo de una tecnología que les gustaría tener, pero que no existe aún. Para ello, utilizaron cartón, pintura, poliestireno, lana y plastilina, que les facilitamos. El Doctor Robot era operado a control remoto por un doctor real, desde otro país; de esta manera, solucionaba la escasez de doctores presentes en la zona y la falta de una posta médica en su comunidad rural. «Ya no hay problema que no haya un doctor», nos dijeron. Más importante aún, el Doctor robot solucionaba el error humano: «El robot no falla como el doctor, hace lo correcto». $\mathrm{Al}$ recordarles que era operado a control remoto por un doctor, argüían que el robot podía detectar si el doctor hacía algo mal y avisar: «El robot anuncia si el doctor se ha olvidado algo». De este modo, los niños revelaban una gran confianza en el poder de las tecnologías, que superaba incluso las limitaciones humanas. Al mismo tiempo, mostraban clara conciencia de los problemas existentes en su comunidad (falta de profesionales médicos en los servicios de salud) y del rol que la tecnología podría cumplir para solucionarlos.

La mirada optimista y positiva en la tecnología se ha popularizado por distintos medios y agentes en los últimos años, por lo cual no debemos considerar a los niños como los únicos en respaldar estas visiones. Sin embargo, de manera simultánea, algunos adolescentes mostraron una conciencia más crítica con respecto a los perjuicios, y no solo los beneficios, de las nuevas tecnologías. Esto se evidenció en algunos de los videos que produjeron para hablarnos del uso de las tecnologías desde sus experiencias. En efecto, y como parte de la metodología propuesta (ver sección metodología), los estudiantes de secundaria realizaron colectivamente un videoreportaje sobre el uso de la tecnología por los jóvenes de su edad. Así, por ejemplo, el grupo de Trujillo creó una historia para mostrar los efectos negativos de la nomofobia o el miedo o ansiedad irracional de salir sin el celular. El grupo de Pucallpa, en su video, combinó beneficios, pero también riesgos del uso de las tecnologías. En este, explicaban cómo a veces niños y jóvenes dejan de jugar al aire libre, realizar deportes y actividad física o se desaprovechan las oportunidades para hacerlo por estar en los videojuegos. Asimismo, señalaron los riesgos de las redes sociales al conectarse con personas que no se conocen, y que quizás pueden engañar a niños y jóvenes, como se reporta en los medios.

Verificamos, entonces, un mayor acceso y uso de las tecnologías entre niños y jóvenes. Este es variado, con un fuerte énfasis en el uso con fines de entretenimiento, un limitado uso educativo, con una mirada positiva en general, pero hay también la emergencia de un reconocimiento de sus posibles impactos «no deseados». 


\section{A modo de conclusión}

En 2008, cuando el programa más ambicioso de introducción de tecnología educativa en las escuelas peruanas se iniciaba, el funcionario a cargo del mismo mostraba un gran optimismo respecto al potencial de las mismas, como lo refleja la siguiente cita:

Hay enfoques que consideran que hay que hacer un programa muy complejo, largo, complicado de capacitación para los maestros para que hagan algo distinto de lo que hacen ahora. El enfoque de la OLPC, que es el que estamos tomando, que es un enfoque que se llama construccionista, lo que hace es integrarse de una manera sencilla, al estilo y a la manera de enseñar. Como dice el analista Poe del New York Times, la maravilla de este programa es que se puede adaptar a un millón de estilos de enseñanza y a un millón de proyectos pedagógicos diferentes. Y eso es lo que hemos notado en el caso de Araway, el maestro incorpora este nuevo recurso a lo que sabe hacer y lo mejora, es decir si teníamos un maestro bueno, ahora va a ser un maestro mejor, si teníamos un maestro más o menos, ahora va a ser más más que menos (Oscar Becerra, en Infordata, 2008) ${ }^{10}$.

Seis años después, tras conversar con cerca de treinta docentes, directores y funcionarios locales, comprobamos que, en efecto, no se ofrecieron «largos, complejos y complicados programas de capacitación» junto con la introducción de las tecnologías. Como resultado, en la mayoría de los casos (con algunas notables excepciones), los maestros -efectivamente- no hacen algo distinto de lo que hacían antes. Han incorporado las XO de manera periférica a su trabajo pedagógico, la usan de manera poco frecuente y como una extensión de otros medios que manejaban antes, exploran poco las posibilidades más propias de los medios digitales (como el trabajo colaborativo en entornos virtuales, la creación de objetos virtuales, o el procesamiento de la información), y mantienen una lógica de control sobre el acceso y uso que tienen los alumnos a las mismas. Esto se debe, en parte, a que son equipos caros y valiosos (material y simbólicamente), que están bajo su responsabilidad y deben cuidar. Así, las evidencias de nuevas prácticas generadas a partir de ellas son todavía pocas y limitadas.

Los estudiantes, por su lado, con un acceso precario y limitado uso de las TIC en el espacio escolar, encuentran que aquella tecnología más directamente destinada a ellos (las XO), si bien tiene juegos y funciones que despiertan su interés, es tan diferente de la del mundo más allá de la escuela, que se ha escolarizado, y ha terminado enmarcada en reglas y procedimientos escolares 
(domesticada y adaptada al espacio que la ha acogido). Por ello, muestran una clara preferencia por las PC y el Windows, las laptops, tabletas y smartphones, que son parte de su vida cotidiana, y cuyo manejo les será requerido en ella, hoy y a futuro. La «maravilla» del programa parece, pues, no haberse materializado. Más aún, y casi como directa respuesta al optimismo de las palabras de Becerra, Toyama nos recuerda que «la tecnología solo amplifica la capacidad pedagógica de los sistemas educativos; puede hacer que las escuelas buenas sean mejores, pero hace que las malas escuelas sean peores» (Toyama, 2011, citado por Villanueva y Olivera, 2012, p. 195).

Las alertas contra una excesiva confianza en las TIC para los problemas educativos del país ya han sido expuestos en diversos estudios y artículos (Warschauer y Ames, 2010; Kraemer et ál., 2009; Bajak, 2012; Cristia et ál., 2012). Este estudio no es ni pretende ser una evaluación de OLPC; no obstante, puesto que es el programa más reciente y masivo de tecnologías educativas en el país, no es posible dejar de mencionar las limitaciones encontradas, particularmente, desde la perspectiva de los propios estudiantes, pues refleja también los problemas más comunes con la tecnología educativa en general.

En efecto, y tomando de manera más amplia todas las tecnologías disponibles en cada institución educativa, encontramos que igualmente estas se utilizan de manera muy limitada por los alumnos, quienes -a pesar de sus críticas- tienen un gran interés en aprender a usarlas y pasar más tiempo en las aulas equipadas con ellas. El acceso precario y el uso limitado que tienen los estudiantes de las tecnologías los hace dependientes de los recursos que puedan encontrar fuera de las aulas. De esta manera, las brechas en las oportunidades iniciales de acceso a la tecnología se amplían en vez de cerrarse, puesto que -como hemos visto- estos recursos están muy desigualmente distribuidos en los diversos entornos que hemos estudiado, y en la sociedad peruana en general. La escuela tiene un importante papel para contrarrestar este proceso, pero la ruta que ha tomado no parece la más efectiva. Aunque es improbable que el Gobierno peruano compre más XO, es posible que nuevas laptops sean adquiridas en un futuro cercano (las Classmates de Intel, por ejemplo, en las que ya han sido capacitados algunos docentes) ${ }^{11}$. Por ello, es necesario extraer lecciones de la experiencia previa para no repetir los mismos errores.

En particular, ha quedado claro que la tecnología por sí sola no produce los cambios esperados, que -lejos de ser una varita mágica- se trata de una práctica social; $y$, en esa medida, produce diferentes resultados según las conductas, valores y significados que los diversos usuarios desplieguen con ella. Para que la tecnología educativa produzca determinados efectos, la metodología que se emplee con ella resulta fundamental, como señala Pedró (2012). Si esta es solo una extensión de la enseñanza verbal tradicional, pocos serán los cambios en el aprendizaje (Ferres, 2000); más aún, las prácticas de uso y apropiación que se generen alrededor de las TIC permitirán el desarrollo de ciertas 
habilidades y no de otras. El equipamiento puede entonces reducir la brecha digital de primer orden (el acceso a las TIC), pero no garantiza per se avances en la brecha de segundo orden (el desarrollo de habilidades informacionales).

Para concluir, este artículo es resultado de una primera reflexión sobre el material recogido en un estudio que todavía está en curso; y, por ello, las conclusiones debieran ser tomadas de manera provisional. Sin embargo, creo que los hallazgos presentados nos muestran una realidad actual, en la cual el enorme interés de los estudiantes por las tecnologías no está siendo aprovechado para reforzar su aprendizaje sobre ellas y con ellas. Encontramos una demanda en los estudiantes, porque hay un reconocimiento de que no todos acceden en igual medida al manejo pleno de las tecnologías. Los estudiantes muestran que podrían aprender todavía muchas cosas de sus maestros, que requieren criterios para manejar, procesar y organizar la gran cantidad de información disponible en la web. Se debe agregar que, sin una orientación clara, los usos recreativos de las tecnologías pueden desplazar largamente a los educativos, o el potencial de los primeros para los segundos desaprovecharse. Urge, entonces, revisar las miradas desde las cuales se trabaja con las tecnologías educativas, con un mayor énfasis en estimular y diversificar las prácticas y comprender y apoyar las necesidades de los contextos de uso de las tecnologías. Hay varias señales de que hay un mayor interés por avanzar en esta dirección, y esperamos que las perspectivas infantiles y juveniles que estamos recogiendo puedan contribuir a ello.

\section{Agradecimientos}

Quisiera agradecer a Carolina Goyzueta, David Landers, Marco Medina y Haydee Velasque, quienes participaron de la investigación sobre la que se basa este artículo. Asimismo, agradezco a Roberto Bustamante de la Digete por su interés en el estudio y comentarios siempre útiles para mejorar su desarrollo. Finalmente, quisiera agradecer a Norma Ramello y Raúl Ames por su apoyo, sin el cual nunca hubiera podido escribir este artículo.

\section{Nota biográfica}

Patricia Ames es Doctoraen AntropologíadelaEducación porlaUniversidad de Londres y Licenciada en Antropología por la Universidad Católica del Perú. Actualmente, se desempeña como profesora de la especialidad de Antropología, Departamento de Ciencias Sociales, en la Pontifica Universidad Católica del Perú. Asimismo, es investigadora principal y Directora de Investigaciones en el Instituto de Estudios Peruanos. 


\section{Referencias}

Bajak, F. (2012) Peru's Laptop Effort Gets Mixed Reviews On Its Effectiveness. Education Week, 18 de julio.

Balarin, M. (2013). Las políticas TIC en los sistemas educativos de América Latina: Caso Perú. Buenos Aires: Unicef.

Barton, D. y Hamilton, M. (1998). Local literacies. Londres: Routledge.

Benitez Larghi, S. y Lemus, M. (2012). Juventud desigualdades y TIC. II Jornadas de Sociología de la Universidad Nacional de La Plata.

Cristiá, J., Cueto, S., Ibarrarán, P., Santiago, A., Severin, E. (2012). Technology and Child Development: Evidence from the One Laptop per Child Program. IDB Working Paper Series No. IDB-WP-304.

Educación en Red (2014). Laptop Classmate: tecnología para el aprendizaje del siglo XXI. Educación en Red.pe, 9 de mayo de 2014. Recuperado de http:// www.educacionenred.pe/noticia/?portada $=53441 \#$ \#xzz3CgIp3nww

Ferrés, J. (2000). Educar en una cultura del espectáculo. Barcelona: Paidós.

García, A., Barreto, M. y Asencio, R. (2013) Control y trasgresión. El uso, apropiación e impacto de las TIC por las mujeres rurales jóvenes en el Perú (Documento de trabajo No. 17 Programa Nuevas Trenzas). Lima: Instituto de Estudios Peruanos.

Gee, J. P. (2004). Situated language and learning: a critique to traditional schooling. NewYork: Routledge.

Gutiérrez, G. (2009). Uso de las computadoras portátiles XO en el desarrollo de los componentes del área de Comunicación Integral en los alumnos del sexto grado de la I.E. $N^{\circ} 30115$ del centro poblado Chucupata en Junín (Tesis de Licenciatura en Educación). Pontificia Universidad Católica del Perú, Lima.

Infordata (2008). Entrevista Oscar Becerra II. YouTube, 16 de febrero de 2008. Recuperado de https://www.youtube.com/watch?v=tO2YUIiZk9Q\&featu re=player_embedded

Kraemer, K., Dedrick, J. y Sharma, P. (2009) One Laptop Per Child: Vision vs. Reality. Communications of the ACM, 52 (6). 66-73.

Lapeyre, J. (2014). El espacio pedagógico de las TIC. XV Encuentro Internacional Virtual Educa Perú 2014, Lima, 9-13 de junio.

Laura, C. (2008) Una laptop por niño en escuelas rurales del Perú: Un análisis de las barreras y facilitadores. Lima: CIES.

Martins, L. T. y Castro, L. R. de (2011). Crianças na contemporaneidade: entre as demandas da vida escolar e da sociedade tecnológica. Revista Latinoamericana de Ciencias Sociales, Niñez y Juventud, 2 (9), 619 - 634.

Ministerio de Educación (2014). OLPC. Perú Educa. Recuperado de http:// www.perueduca.edu.pe/olpc/OLPC_Dist.html 
Pedró, F. (2012) Tecnología y escuela: lo que funciona y por qué. Lima: Fundación Santillana.

Prensky, M. (2001). Digital Natives, Digital Immigrants. On the Horizon, MCB University Press, 9 (5).

Trinidad, R. (2005) Entre la ilusión y la realidad: las nuevas tecnologías en dos proyectos educativos del Estado. Lima: Instituto de Estudios Peruanos.

Trinidad, R. y Rodrígues, H. (2012) Investigación comparativa sobre los usos y disfrute de Internet por niños y niñas de entre 8 y 10 años, en tres colegios de Argentina, Perú y Paraguay. Lima: Save the Children Suecia.

Santiago, A., Severin, E., Cristia, J., Ibarrarán, P., Thompson, J. y Cueto, S. (2010) Evaluación experimental del programa Una Laptop por Niño en Perú. Aportes, División de Educación del Banco Interamericano de Desarrollo, julio, (5).

Street, B. (1993). Cross-cultural approaches to literacy. Cambridge: Cambridge University Press.

(1995). Social Literacies: Critical Approaches to literacy in ethnography and development. New York: Longman.

(2000). Literacy events and literacy practices: Theory and practice in the New Literacy Studies. En Jones, K. y Martin-Jones, M. (Eds.), Multilingual Literacies. Reading and writing different worlds (17-29). Philadelphia: John Benjamins Publishing Company.

Street, B. y Street, J. (2004). La escolarización de la literacidad. En Zavala, V., Niño-Murcia, M. y Ames, P. (Ed.), Escritura y Sociedad: nuevas perspectivas teóricas y etnográficas. Lima: Red para el Desarrollo de las Ciencias Sociales.

Unwin, T. (2014) The damaging mythology of «Digital Natives». Uniwin. Recuperado de http://unwin.wordpress.com/2014/08/10/the-damaging-mythology-of-digital-natives/

Villanueva, E. y Olivera, P. (2012). Barreras Institucionales para el Desarrollo de una Innovación: Evaluando la Implementación de las Computadoras $\mathrm{XO}-1$ en dos Escuelas Periurbanas del Perú. Information Technologies \& International Development [Edición Especial Bilingüe: Investigación sobre TIC4D en Latinoamérica], 8 (4), 191-203.

Warschauer, M. y Ames, M. (2010) Can one laptop per child save the world's poor? Journal of International Affairs. Fall/Winter 2010, 64 (1). New York, The Trustees of Columbia University. 